\title{
First report of Groundnut ringspot tospovirus in Paraguay
}

\author{
A. F. Esquivel ${ }^{1}$ (1) • V. M. Camelo-García ${ }^{1}$ - J. A. M. Rezende ${ }^{1}$ - E. W. Kitajima ${ }^{1}$ - L. R. González ${ }^{2} \cdot$ H. Sarubbi ${ }^{2}$
}

Received: 18 January 2019 / Accepted: 4 March 2019 / Published online: 12 March 2019

(C) Australasian Plant Pathology Society Inc. 2019

\begin{abstract}
Tospovirus can lead to major yield losses in several crops worldwide. This work describes the identification of a tospovirus infecting tomato and petunia plants. Based on molecular assays, the virus was identified as Groundnut ringspot tospovirus (GRSV). To our knowledge, this is the first report of GRSV in Paraguay.
\end{abstract}

Keywords Solanaceae $\cdot$ Tospovirus $\cdot$ Diagnose

The "vira cabeza" disease is one of the most wellknown tomato viral diseases among tomato producers in Paraguay and worldwide. Common tospovirus species found in South America causing this disease are Tomato spotted wilt tospovirus (TSWV), Tomato chlorotic spot tospovirus (TCSV) and Groundnut ringspot tospovirus (GRSV) (Gilbertson et al. 2015). Although characteristic tospovirus-like symptoms have been frequently observed in tomato fields, no molecular identification of tospovirus isolates present in Paraguay is available. In 2018, tomato plants (var. Santa Clara) showing typical tospovirus-like symptoms including chlorotic spots, concentric and necrotic rings on the leaves and stunting (Fig. 1a), were found in high incidence (ca 50\%), at the experimental field of the National University of Asuncion (UNA), San Lorenzo County, Central Department, Paraguay. At the same time, flower growers of Luque County, Central Department, were forced to eliminate entire sets of tospovirus-like symptomatic petunias (Petunia hybrida)

A. F. Esquivel

arnaldo.esquivel@usp.br

1 Departamento de Fitopatologia e Nematologia, ESALQ/USP, Piracicaba, SP 13418-900, Brazil

2 Departamento de Biología, FCA/UNA, San Lorenzo, Paraguay
(Fig. 1b) (around 500 plants per set). Samples of symptomatic leaves were collected from 10 plants of each species for diagnosis. Leaf extracts were first serologically analysed by plate-trapped antigen - enzyme linked immunosorbent assay (PTA-ELISA), using polyclonal antiserums produced against the nucleocapsid protein of TSWV, TCSV and GRSV, kindly provided by Dr. Alice K. Inoue-Nagata, Embrapa, CNPH, DF, Brazil. Average absorbance values for each antiserum were 0.5 (TSWV), 0.7 (TCSV) and 0.8 (GRSV), in tomato samples and 0.7 (TSWV), 0.8 (TCSV) and 1.2 (GRSV) in petunia, while negative control values were between 0.01 and 0.04 for all antisera. Total RNA was extracted from all leaf samples using the Purelink viral RNA/DNA kit (Thermo Fisher Scientific), according to the manufactures protocol. RT-PCR was performed with the primers BR60 (5'-CCCGGATCCTGCAG AGCAATTGTGTCA-3') and BR65 (5'-ATCAAGCC TTCTGAAAGTCAT-3'), which enables the amplification of a genomic region of 453 bp (Fig. 2) of the $S$ RNA of tospoviruses, corresponding to part of the nucleocapsid gene $(\mathrm{N})$ and the 3' UTR (Eiras et al. 2001). Amplicons were generated from all symptomatic plants; two of these amplicons of each plant species were purified and directly sequenced in both directions at Macrogen Inc., Korea. The consensus of the nucleotide sequences were obtained using the Electropherogram quality analysis program (http:// asparagin.cenargen.embrapa.br/phph/). The viral nucleotide sequences from tomato (MK140505- 
Fig. 1 Symptoms of Groundnut ringspot tospovirus on leaves of naturally infected (a) Solanum lycopersicum and (b) Petunia hybrida

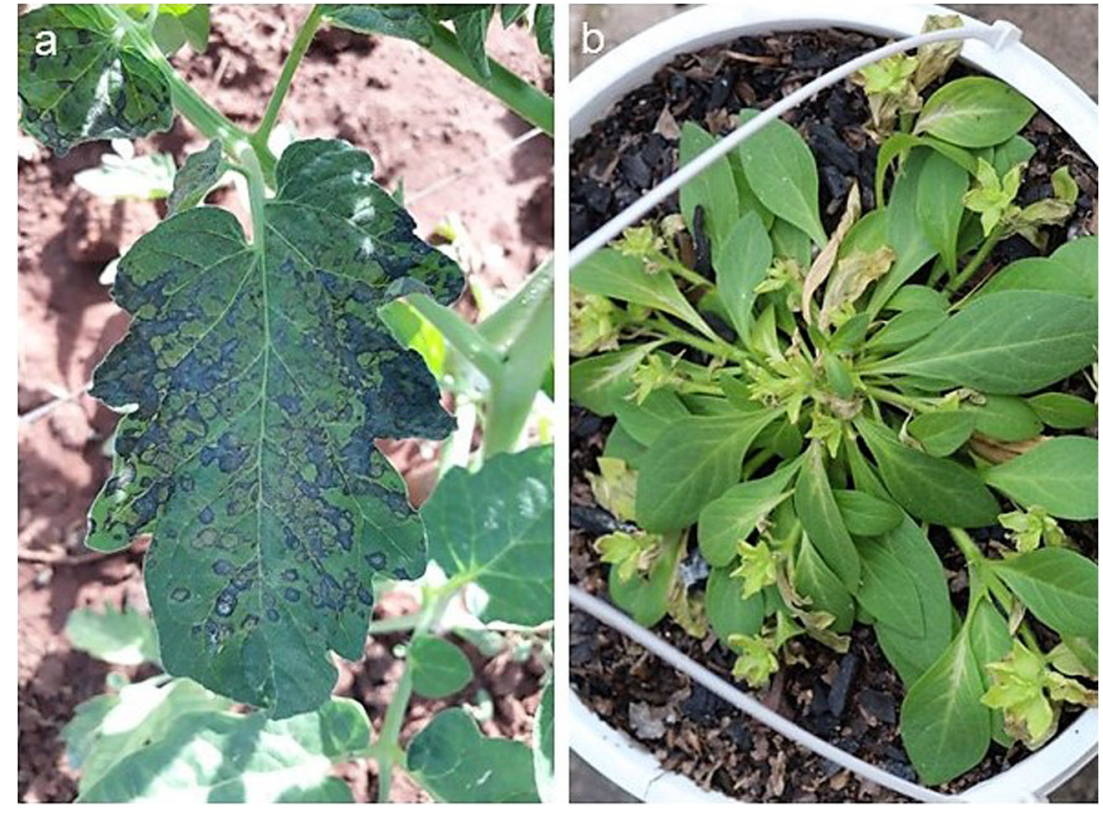

MK140506) and petunia (MK140507- MK140508) were compared with the corresponding sequences of other tospoviruses available in GenBank using BLASTn. They showed 96-98\% identity with corresponding nucleotide sequences of GRSV isolates from Argentina and Brazil (U49698.1, KY400110). Leaf samples of naturally infected petunia plants were processed to obtain ultra-thin sections, which were examined under transmission electron microscope. The presence of pleomorphic particles of 80 to $120 \mathrm{~nm}$ in diameter, typical of tospovirus were confirmed (Fig. 3). To our knowledge, this is the first report of GRSV in Paraguay. Studies should be carried out to develop disease management strategies, according to local growing conditions, which consequently can minimise damage to crops of both species.

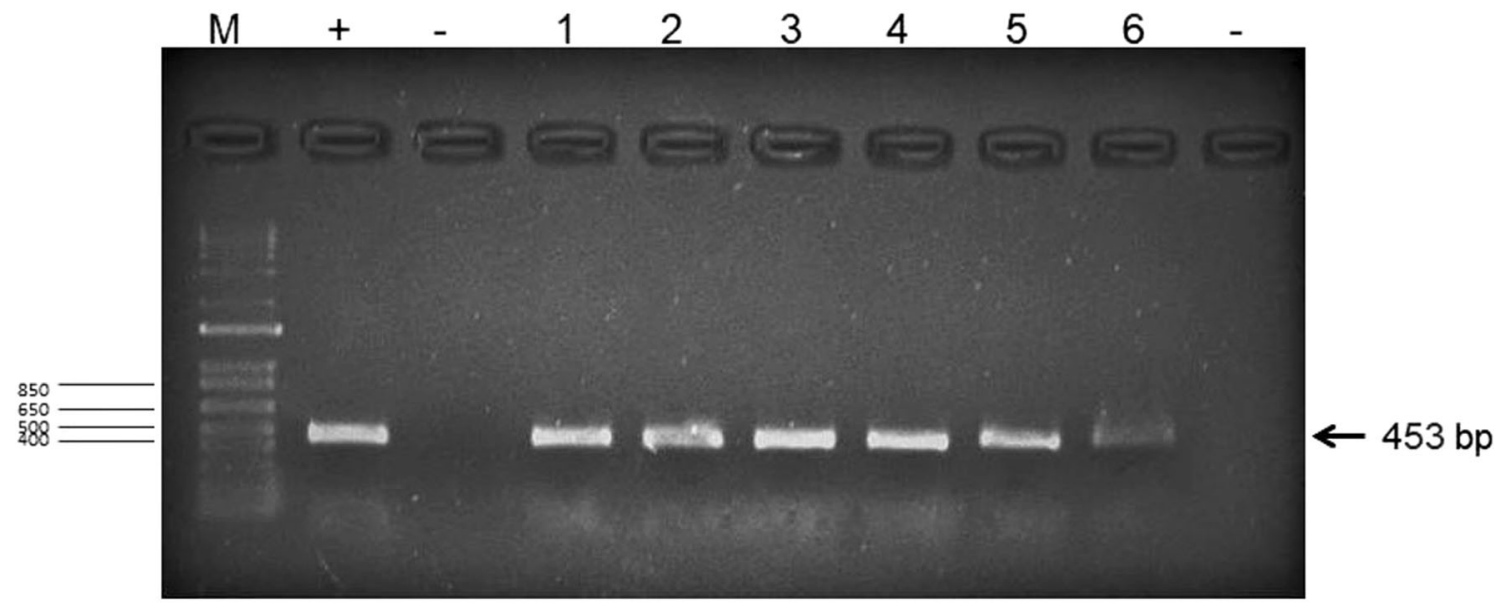

Fig. 2 Agarose gel showing the results of the detection of Groundnut ringspot tospovirus by RT-PCR in tomato (Solanum lycopersicum) (1-3) and petunia (Petunia hybrida) (4-6) samples. +: control infected with GRSV, -: healthy controls 


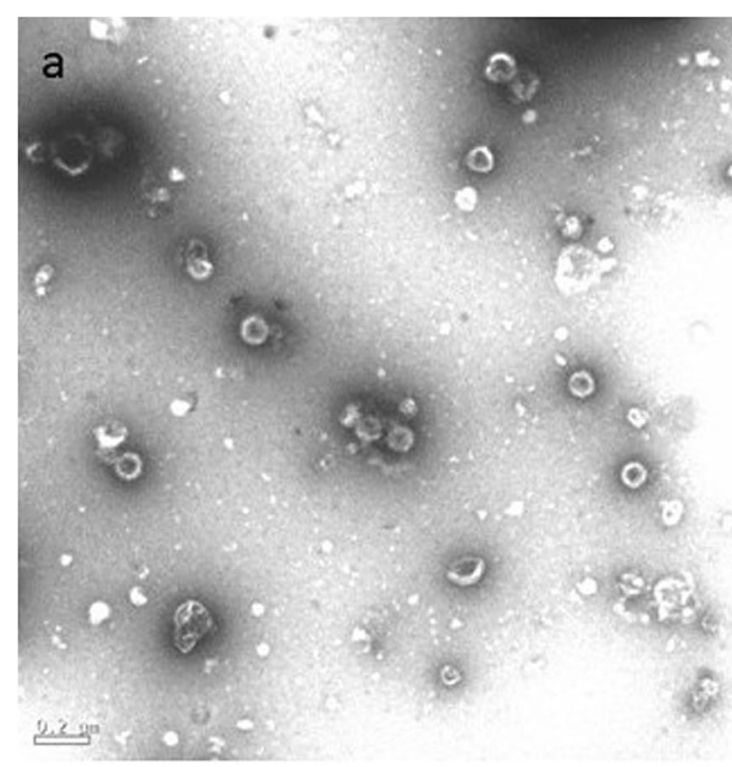

Fig. 3 Transmission electron micrographs of Groundnut ringspot tospovirus (GRSV) in infected petunia (Petunia hybrida) leaves. a Negatively stained leaf extract, showing a group of presumed membrane-bounded GRSV virions, with circular profile ca. $100 \mathrm{~mm}$ in

\section{References}

Eiras M, Resende RO, Missiaggia AA, Avila AC (2001) RT-PCR and dot blot hybridization methods for a universal detection of tospoviruses. Fitopatol Bras 26:170-175. https://doi.org/10.1590/s010041582001000200009

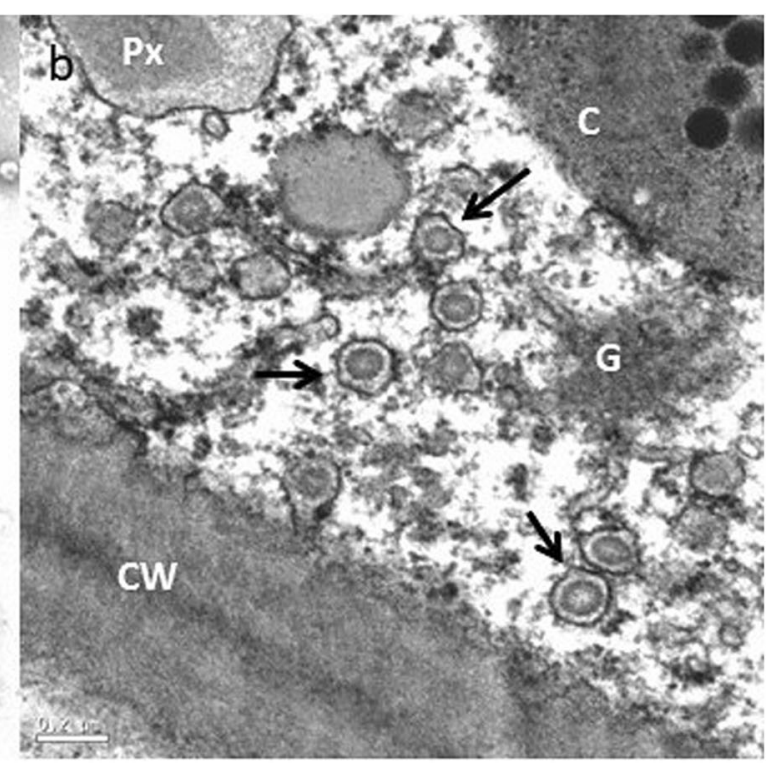

diameter. b Thin section of a leaf mesophyll parenchymal cell showing presumed GRSV virions (arrows) within membrane bounded cisternae of the endoplasmic reticulum. C- chloroplast; CW- cell wall; G- Golgi complex; Px- peroxisome

Gilbertson RL, Batuman O, Webster CG, Adkins S (2015) Role of the insect supervectors Bemisia tabaci and Frankliniella occidentalis in the emergence and global spread of plant viruses. Annu Rev Virol 2:67-93. https://doi.org/10.1146/annurevvirology-031413-085410 